\title{
A Case of Community-Onset Bacterial Meningitis due to Extended-Spectrum Beta-Lactamase Producing Escherichia coli
}

\author{
Yusuke Yoshino ${ }^{\mathrm{a}, \mathrm{b}}$, Kazunori Seo ${ }^{\mathrm{a}}$, Ichiro Koga ${ }^{\mathrm{a}}$, Takatoshi Kitazawa ${ }^{\mathrm{a}}$, Yasuo Ota ${ }^{\mathrm{a}}$
}

\begin{abstract}
This is a case of community-onset bacterial meningitis caused by an extended-spectrum beta-lactamase-producing Escherichia coli that was resistant to ceftazidime, cefpirome, and aztreonam. Multidrugresistant gram-negative bacilli, such as the $E$. coli in our study, are now spreading in many medical fields and may possibly become pathogens of community-onset meningitis. Our findings with this case and previously published reports indicate that empiric therapy with carbapenems may represent a suitable management option for future cases of meningitis due to gram-negative bacilli.
\end{abstract}

Keywords: Extended-spectrum beta-lactamase (ESBL); Meningitis; Carbapenem

\section{Introduction}

Bacterial meningitis is one of the several serious infectious diseases, which has high mortality rate [1]. It is well known that empiric antibiotic therapy is required because treatment must be initiated as soon as possible for the patient to survive the meningitis. The treatment guideline for bacterial meningitis also recommends that empiric antibiotic treatment should be initiated immediately [2].

Multidrug-resistant gram-negative bacilli (GNB) have become a major public health threat [3]. Beta-lactamaseproducing GNB are particularly important pathogens be-

Manuscript accepted for publication May 23, 2013

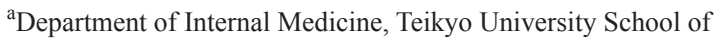
Medicine, 2-11-1 Kaga, Itabashi-ku, Tokyo 173-8606, Japan

${ }^{\mathrm{b}}$ Corresponding author: Yusuke Yoshino, Department of Internal Medicine, Teikyo University School of Medicine, 2-11-1 Kaga, Itabashi-ku, Tokyo 173-8606, Japan.

Email: yyoshino@med.teikyo-u.ac.jp

doi: http://dx.doi.org/10.4021/jmc1362e cause of their resistance to beta-lactam antibiotics. Extended-spectrum beta-lactamase (ESBL) is one of the major beta-lactamases, which can confer resistance to the fourthgeneration cephalosporins. In some clinical fields, ESBLproducing GNB have begun to make the choice of empirical antibiotic regimens difficult. It has recently been reported that ESBL-producing GNB have become prevalent in the stools of healthy volunteers $[4,5]$.

Here, we report an adult hemodialysis patient with community-acquired bacterial meningitis due to ESBL-producing Escherichia coli. Community-acquired meningitis due to GNB in adult patients is rare, and particularly, meningitis due to ESBL-producing GNB has been reported in only a few cases $[6,7]$. We also reviewed previously published reports to demonstrate the importance of ESBL-producing GNB in community-acquired meningitis.

\section{Case Report}

A 63-year-old Japanese man with fever and disturbance of consciousness was admitted to the emergency room of our hospital. The patient had previously been diagnosed with chronic renal failure and was initiated with artificial hemodialysis at the age of 55 years. The patient had also been diagnosed with choledocholithiasis and cholangitis at the age of 61 years. Endoscopic sphincterotomy and antibiotic treatment were performed at that time, at another hospital. After sphincterotomy, he was treated for cholangitis with levofloxacin twice before admission. On admission to our hospital, the patient's temperature was $39.0{ }^{\circ} \mathrm{C}$, his heart rate was 124/min (regular), and he had a disturbance of consciousness (Glasgow Coma Scale; E4V4M6). He also had a stiff neck. His pupil size (diameter) was $2.5 \mathrm{~mm} / 2.5$ $\mathrm{mm}$, and light reflex was positive in both eyes. There was no evidence of heart murmur or lung rale. There were no other abnormal findings. Chest/abdominal radiographs and brain computed tomography upon admission revealed normal findings. Blood tests revealed a white blood cell (WBC) count of 18,700 cells $/ \mu \mathrm{L}$ and a C-reactive protein (CRP) level of $14.48 \mathrm{mg} / \mathrm{dL}$; however, there were no other significant findings in the blood and urine tests indicating the focus 
Table 1. Drug Susceptibility Test of E. coli in Our Case

\begin{tabular}{|c|c|c|}
\hline Drug & $\operatorname{MIC}(\mu \mathrm{g} / \mathrm{mL})$ & Susceptibility \\
\hline Ampicillin & $>16$ & $\mathrm{R}$ \\
\hline Piperacillin & $>64$ & $\mathrm{R}$ \\
\hline Amoxicillin-clavulanate & 16 & I \\
\hline Cefazolin & $>16$ & $\mathrm{R}$ \\
\hline Cefotium & $>16$ & $\mathrm{R}$ \\
\hline Cefotaxime & $>32$ & $\mathrm{R}$ \\
\hline Ceftazidime & $>16$ & $\mathrm{R}$ \\
\hline Cefpirome & $>16$ & $\mathrm{R}$ \\
\hline Cefmetazole & $\leq 4$ & $\mathrm{~S}$ \\
\hline Cefaclor & $>16$ & $\mathrm{R}$ \\
\hline Cefcapene-pivoxil & $>1$ & $\mathrm{R}$ \\
\hline Flomoxef & $\leq 8$ & $\mathrm{~S}$ \\
\hline Cefoperazone-sulbactam & $>16$ & $\mathrm{R}$ \\
\hline Imipenem-cilastatine & $\leq 1$ & $\mathrm{~S}$ \\
\hline Aztreonam & $>16$ & $\mathrm{R}$ \\
\hline Gentamicin & $>8$ & $\mathrm{R}$ \\
\hline Amikacin & $\leq 4$ & $\mathrm{~S}$ \\
\hline Levofloxacin & $>4$ & $\mathrm{R}$ \\
\hline Trimethoprim-sulfamethoxazole & $\leq 2$ & $\mathrm{~S}$ \\
\hline
\end{tabular}

MIC: minimum inhibitory concentration.

of infection. We also collected cerebrospinal fluid (CSF) on admission. The leukocyte count in the CSF was 6,420 cells/ $\mathrm{mm}^{3}$, with a predominance of polynuclear leukocytes.

The patient was diagnosed with meningitis. Blood was collected twice, once after admission and once before the administration of antibiotic agents, for culturing. Intravenous ceftriaxone ( $2 \mathrm{~g}$ every $12 \mathrm{~h}$ ) and vancomycin ( $1 \mathrm{~g}$ after hemodialysis) were administered from the day of admission. Dexamethasone (10 mg every $6 \mathrm{~h}$ ) was also administered.

Gram stain of the CSF was performed the day after admission, and GNB were detected. Two days after admission, blood and CSF cultures revealed ESBL-producing E. coli that was multidrug resistant (Table 1). We changed the antibiotic regimen from ceftriaxone and vancomycin to meropenem $(1 \mathrm{~g}$ every $24 \mathrm{~h})$. After the administration of meropenem, the patient's symptoms, including fever, neck stiffness, and disturbance of consciousness, improved gradually. His WBC count and CRP level also decreased. Six days after admission, the leukocyte count in his CSF was 146 cells/ $\mathrm{mm}^{3}$, and administration of dexamethazone was terminated. On day 21 after admission, the leukocyte count in his CSF was 123 cells $/ \mathrm{mm}^{3}$ and the patient's symptoms continued to improve. However, on day 24 after admission, the patient developed acute purulent cholangitis diagnosed by laboratory findings and abdominal ultrasonography, which resulted in his death, even though meropenem was administered.

\section{Discussion}

Community-onset meningitis due to ESBL-producing GNB has been rare [8]. Some neonatal cases, including outbreak case series, were reported because $E$. coli was one of the major pathogens responsible for meningitis in neonates. In contrast, only two cases of community-acquired meningitis due to ESBL-producing GNB have previously been reported 


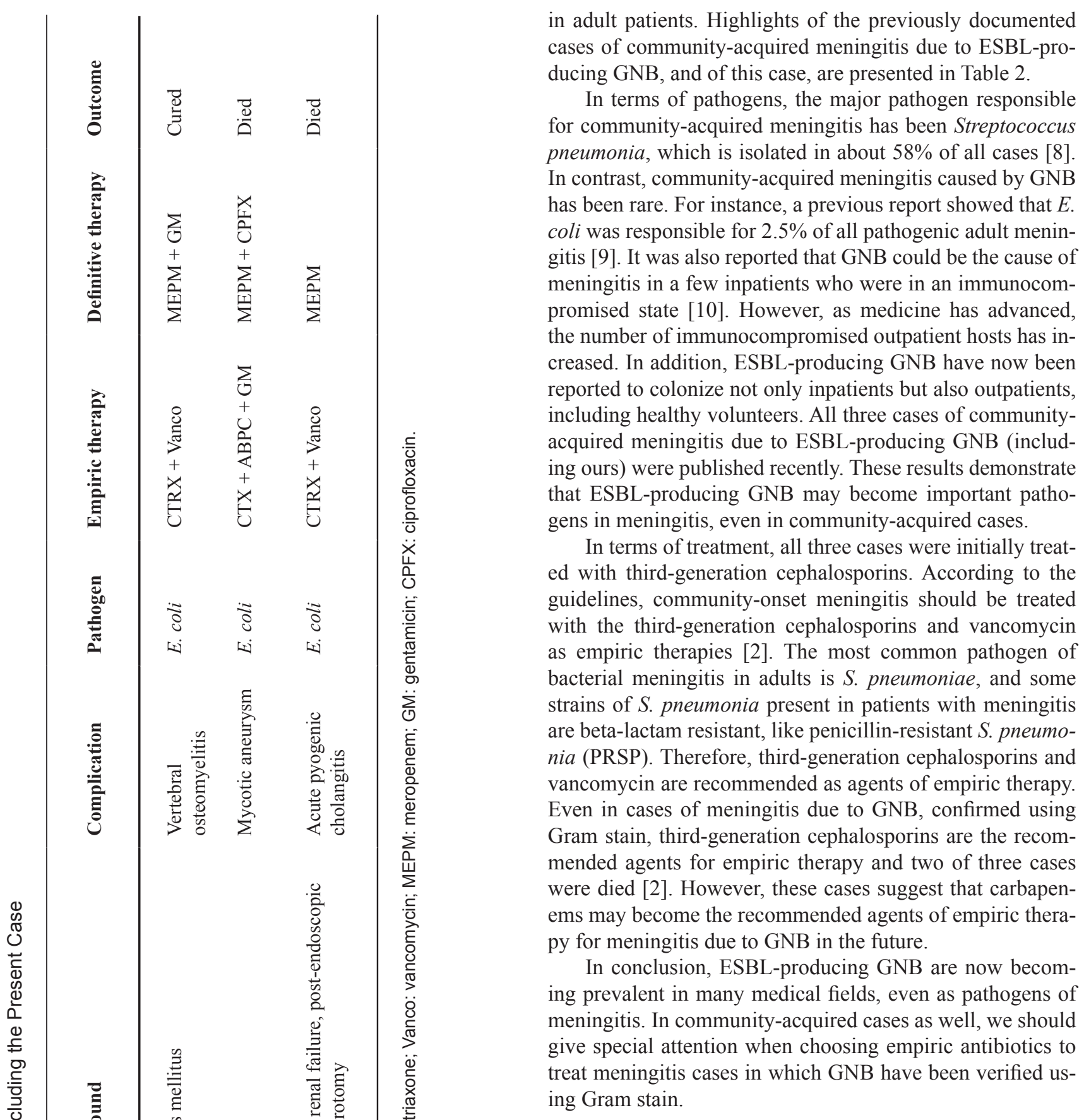

\section{Authors' Contributions}

The manuscript was prepared by YY under the supervision of YO. KS, IK and TK helped to draft the manuscript. All authors read and approved the final manuscript.

\section{Conflict of Interest}

None. 


\section{References}

1. van de Beek D, de Gans J. Dexamethasone in adults with community-acquired bacterial meningitis. Drugs. 2006;66(4):415-427.

2. Tunkel AR, Hartman BJ, Kaplan SL, Kaufman BA, Roos KL, Scheld WM, Whitley RJ. Practice guidelines for the management of bacterial meningitis. Clin Infect Dis. 2004;39(9):1267-1284.

3. Masterton RG, Turner PJ. Trends in antimicrobial susceptibility in UK centres: the MYSTIC Programme (1997-2002). Int J Antimicrob Agents. 2006;27(1):6972.

4. Tian SF, Chen BY, Chu YZ, Wang S. Prevalence of rectal carriage of extended-spectrum beta-lactamase-producing Escherichia coli among elderly people in community settings in China. Can J Microbiol. 2008;54(9):781785 .

5. Valverde A, Coque TM, Sanchez-Moreno MP, Rollan A, Baquero F, Canton R. Dramatic increase in prevalence of fecal carriage of extended-spectrum beta-lactamaseproducing Enterobacteriaceae during nonoutbreak situations in Spain. J Clin Microbiol. 2004;42(10):4769-
4775.

6. Gon Y, Otsubo R, Murase S, Park K, Nakazawa K, Hara H. [Case of an elderly patient with community acquired bacterial meningitis due to extended spectrum beta lactamase producing Escherichia coli]. Rinsho Shinkeigaku. 2012;52(1):12-18.

7. Weyrich P, Ettahar N, Legout L, Meybeck A, Leroy O, Senneville E. First initial community-acquired meningitis due to extended-spectrum beta-lactamase producing Escherichia coli complicated with multiple aortic mycotic aneurysms. Ann Clin Microbiol Antimicrob. 2012;11:4.

8. Thigpen MC, Whitney CG, Messonnier NE, Zell ER, Lynfield R, Hadler JL, Harrison LH, et al. Bacterial meningitis in the United States, 1998-2007. N Engl J Med. 2011;364(21):2016-2025.

9. Hussein AS, Shafran SD. Acute bacterial meningitis in adults. A 12-year review. Medicine (Baltimore). 2000;79(6):360-368.

10. Cuenca M, de Andres R, de Gorgolas M, Gadea I, Molleja AS, Fernandez Guerrero ML. [Spontaneous meningitis caused by gram-negative bacilli]. Rev Clin Esp. 1997;197(9):618-622. 